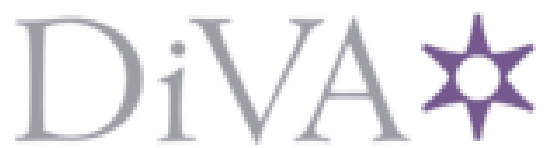

http://www.diva-portal.org

\title{
Postprint
}

This is the accepted version of a paper published in International Journal of Retail \& Distribution Management. This paper has been peer-reviewed but does not include the final publisher proof-corrections or journal pagination.

Citation for the original published paper (version of record):

Hagberg, J., Sundström, M., Nicklas, E-Z. (2016)

The digitalization of retailing: an exploratory framework

International Journal of Retail \& Distribution Management, 44(7): 694-712

https://doi.org/10.1108/IJRDM-09-2015-0140

Access to the published version may require subscription.

N.B. When citing this work, cite the original published paper.

Permanent link to this version:

http://urn.kb.se/resolve?urn=urn:nbn:se:hb:diva-11866 


\section{The digitalization of retailing: an exploratory framework}

\section{Introduction}

Digitalization $^{[1]}$ is one of the most significant on-going transformations of contemporary society and encompasses many elements of business and everyday life. This transformation is important for the retail sector, which both affects and is affected by this development. Retailers provide consumers with various digital products and services that are adapted to the use of digital technologies and are simultaneously affected by the new forms of consumption associated with these digital technologies. While digitalization has a long history in retailing (see, e.g., Salkin, 1964; Watson, 2011), the significance of the transformation is becoming increasingly visible.

With the emergence of the Internet, scholars have taken great interest in the implications for retailing (e.g., Alba et al., 1997; Peterson et al., 1997; Burt and Sparks, 2003). These implications include changing business opportunities (e.g., Quelch and Klein, 1996), business models (e.g., Osterwalder and Pigneur, 2002; Sorescu et al., 2011), forms of commerce (Gloor, 2000), purchasing processes (Grewal et al., 2013), and the transformation of local shops into global markets (Wrigley and Currah, 2006). Nonetheless, digitalization has so far primarily been addressed in terms of e-commerce. Although e-commerce is part of digitalization, its impact extends far beyond e-commerce and includes the transformation of physical products into digital services, consumer recommendations in social media, and the incorporation of digital devices into the purchasing process-such as online information searches leading to offline purchases (see, e.g., Pauwels et al., 2011).

A central facilitator of these broader effects of digitalization is the increasing use of mobile devices that connect to the Internet, which have begun to change consumer practices, including shopping behaviours in fixed store settings. New consumer products with mobile Internet access are launched at a rapid pace, often linking to other technologies (Cochoy, 2012), and mobile devices are becoming increasingly important in the retail setting (Shankar et al., 2010). Although mobile devices may work as a substitute for activities previously performed by laptops, they also provide additional features, such as barcode scanning, location-based services, and near field communication (Ström et al., 2014). These mobile devices are converting the Internet into an element in physical stores (Bodhani, 2012), which has driven the emergence of new retail formats, such as pop-up stores (Kim et al., 2010) and click-and-drive purchasing (Colla and Lapoule, 2012), in addition to enabling information retrieval, testing, ordering, payment, and various services in brick-and-mortar stores. The popularity of mobile devices has also driven the development of applications for payments and price comparisons and access to product information. Thus, digitalization is likely to have a far-reaching effect on retailers, consumers, employees, and society, and there is a significant need for a broad understanding of the phenomenon.

Nonetheless, the scholarly conversation about the digitalization of retailing has largely been limited to specific aspects of digitalization and primarily to e-commerce. The research that has moved beyond ecommerce has focused on narrow aspects of digitalization, including the use of mobile devices for marketing purposes (e.g., Shankar and Balasubramanian, 2009; Shankar et al., 2011; Ström et al., 2014) and the utilization of digital technologies in stores, such as digital signage, interactive kiosks, and radio-frequency identification (RFID) (e.g., Shankar et al., 2011; Dennis et al., 2013). There is, however, a paucity of studies that analyse the more all-encompassing transformations of digitalization and the longer-term and bigger picture implications and effects of digitalization on retailing (for an exception, see, e.g., Piotrowicz and Cuthbertson, 2014). This scarcity is problematic given the potentially far-reaching effects that digitalization might have on the retail industry.

The purpose of this paper is to fill this research gap by analysing how retailing is transformed by digitalization. We undertake this task by 1) developing a conceptual framework consisting of four elements of the retailer-consumer interface: exchanges, actors, offerings, and settings; 2) describing and exemplifying how digitalization transforms each of the elements included in the framework based on the previous literature; and 3) identifying implications for future research in order to further delineate the transformation of retailing due to digitalization. 
The paper is structured as follows. In the next section, we introduce the notion of digitalization and focus on the retailer-consumer interface. Thereafter, we introduce our conceptual framework, which is built on the following elements: i) retailing exchanges and the manner in which communication, transactions, and distribution occur (cf. Peterson et al., 1997); ii) the nature of retail offerings and what constitutes the actual offering; iii) retail settings, i.e., where and when retailing takes place; and iv) the actors who participate in retailing. In the four sections that follow, we describe each of the elements included in the framework based on the recent retailing literature. These sections are followed by a concluding discussion with theoretical and practical implications as well as limitations and suggestions for future research.

\section{Digitalization and the retailer-consumer interface}

In this paper, 'digitalization' refers broadly to the integration of digital technologies into retailing, as in the following definition: 'Digitalization: Integration of digital technologies into everyday life by the digitization of everything that can be digitized' [Businessdictionary.com 2014-10-22]. Although this general term involves all types of digital technologies, we focus on the integration of Internetconnected digital technologies in particular and on the interface between retailers and consumers. The integration of digital technologies in retailing can mean a slight transformation of previously existing activities, processes, actors, and goods but may also introduce new types of products, services, etc. Thus, digitalization refers both to a transformation from 'analogue' to 'digital' (e.g., a shift from cash to electronic payments) and to the facilitation of new forms of value creation (e.g., accessibility, availability, and transparency) (Amit and Zott, 2001). Employing the notion of 'digitalization' rather than 'digital' implies that this transformation is on-going and has no clear beginning or end. Thus, we approach the notion of digitalization as something that is emerging and in the making rather than something already achieved (e.g., Hagberg, 2008). In line with Fors (2010), we conceive digitalization as an open and dynamic concept that has not been fully defined; it is an on-going process that should be approached with sensitivity and openness to what it might encompass. What Moisander and Eriksson (2006: 258) said about the information society is equally applicable to digitalization: it is 'not merely something that is imposed on people and organizations but something that people and organizations "do" and produce themselves through everyday practice and social interaction'. Digitalization is not something that takes place 'outside' of retailing and is then transferred to retailing (which the notions of 'impact' and 'effects' would wrongly suggest) but is an on-going transformation of retailing to be studied from 'within'.

Of course, digitalization is not a new phenomenon in retailing; indeed, it has been an important part of retailing - and changes in retailing - since at least the 1970s (see, e.g., Watson, 2011) through electronic cash systems, barcodes, point-of-sale data, EDI with suppliers, etc. Although many of these previous changes were relatively invisible to consumers, today's changes brought on by digitalization involve the consumer. For example, the use of barcodes has been part of important changes in supply channels, product packages, and store information systems but has less meaning for customers directly. With the spread of mobile devices, however, these same barcodes can be used in many other ways that more actively involve customers. Of course, digitalization is not an entirely new phenomenon on the consumer side, either. With the proliferation of PCs in homes and the increase in different forms of digital devices, Internet technologies, etc., the transformation has been underway for decades. Thus, although retailers and consumers previously experienced digitalization relatively independently of one another, it now involves the retailer-consumer interface to a greater extent. This interface is, therefore, the object of our focus.

\section{Conceptual framework}

To capture the increasing importance of digitalization for the retailer-consumer interface, we base our conceptual framework on the analysis of consumption developed by Ritzer (2001) and Lehdonvirta (2012). Ritzer (2001) outlines four elements of consumption: processes, sites, subjects, and objects. These elements are further developed by Lehdonvirta (2012) within the context of digitalization. We use a similar breakdown as our starting point but with slight changes in terminology. Instead of processes, we use the concept of exchange to refer to the various activities taking place at the retailerconsumer interface. Exchange is considered neutral here - it does not adopt a particular actor role or 
view (i.e., retailer or consumer) as a starting point. We use the concept of setting instead of sites to refer to the different situations in which retailing occurs. We use the concept of actors instead of subjects to encompass not only consumers but also retailers. As the relationship between consumers and retailers is transformed by digitalization, using the concept of actors allows for an exploration of less clear-cut roles and identities. For example, Hagberg (2010) shows how actors in e-commerce exchanges are configured differently and that 'actors' are not necessarily human; instead, 'actors' are the assembly of different entities that participate in the exchange (including, for example, digital devices in the store or at home). Finally, we use the concept of offering in place of objects to refer to both products and services and to stress that products and services may be transformed by digitalization. Drawing on studies exploring modes of exchange in retailing (Kjellberg and Helgesson, 2007; Hagberg, 2010), we propose that there are symbiotic relationships between the four different elements and that changes in one of the elements potentially contribute to changes in the other elements. Figure 1 graphically presents our framework, and each element is developed further below on the basis of the previous literature.

[Figure 1 here]

\section{Literature employed}

The literature consists of papers in retailing, consumption and marketing journals complemented by other academic work identified through this literature. We used the databases Scopus and Business Source Premiere to identify recent works using a combination of keywords, including retail*, digital*, internet*, and consumer*, followed by more specific searches based on the elements included in the framework and by scrolling the content of the journals directly. The targeted journals are as follows (with the number of articles employed in parentheses): Journal of Retailing (10), Journal of Retailing and Consumer Services (10), Journal of Consumer Culture (8), International Journal of Retail \& Distribution Management (5), Journal of Interactive Marketing (5), Journal of Marketing Management (5), Consumption Markets \& Culture (4), Marketing Theory (4), Industrial Marketing Management (3), Journal of Business Research (3), Journal of Marketing (3), The International Review of Retail, Distribution and Consumer Research (3), MIT Sloan Management Review (2), AI and Society (1), Computer Networks (1), Decision Support Systems (1), Design Management Journal (1), Environment and Planning A (1), European Journal of Marketing (1), Geoforum (1), Harvard Business Review (1), Information Society (1), International Journal of Electronic Commerce (1), Journal of Consumer Marketing (1), Journal of Consumer Policy (1), Journal of Economic Perspectives (1), Journal of Industry, Competition and Trade (1), Journal of Macromarketing (1), Journal of Marketing Channels (1), Journal of Research in Interactive Marketing (1), Journal of the Academy of Marketing Science (1), Mobile Media \& Communication (1), Strategic Management Journal (1), Theory, Culture and Society (1), Transport Reviews (1), and Transportation (1). Below, we first present a summary of the literature employed followed by an analysis of how each element is transformed due to digitalization.

[Insert Table 1 about here]

\section{Element I: Digitalization of exchanges}

With the emergence of the Internet during the late 1990s, new companies arose that were focused on e-commerce. Soon, however, many retail chains established e-commerce sites, while many ecommerce firms simultaneously established fixed stores; thus, there was an emergence of so-called multi-channel retailing (e.g., Reynolds, 2002; Schoenbachler and Gordon, 2002). In recent years, the notion of multi-channel retailing has gradually shifted to a focus on omni-channels (e.g., Brynjolfsson et al., 2013; Pantano and Viassone, 2015; Verhoef et al., 2015). Importantly, the concept of multichannels implies a separation between channels (although they are combined), whereas the omnichannel concept is more focused on customers and on providing them with the ability to move between 'channels' seamlessly during one integrated purchasing process (e.g., Piotrowicz and 
Cuthbertson, 2014; Verhoef et al., 2015). In order to analyse the relationships between channels, exchanges can be divided into three facets: communication, transaction, and distribution (Peterson et al., 1997). Communication involves access to and the exchange of information. Transaction involves the transfer of ownership, including monetary transactions and the actual purchase. Distribution refers to the physical and tangible exchanges of products. This division is akin to Rotem-Mindali and Weltevreden's (2013) framework of information gathering, purchasing, and delivery, as well as Grewal et al.'s (2013) framework of pre-purchase, purchase, and post-purchase; nonetheless, it is more neutral because it does not assume any specific actor's perspective.

\section{Changes of communication channels}

Digitalization has begun to transform several forms of communication in the retailer-consumer interface (Grewal et al., 2013; Yadav and Pavlou, 2014); examples range from loyalty programmes (Coll, 2013) to digital coupons (Hyunjoo and Young, 2015). However, it is not only the direct communication between retailers and consumers that is becoming digitalized but also the communication between consumers through social media or various forms of third-party communication (e.g., Zhou and Duan, 2015). Third parties have increased consumers' access to price information and improved their ability to compare prices among different retailer offerings and assortments (Jung et al., 2014). Because these price comparisons can also be conducted in a fixedstore setting with the proliferation of digital mobile devices, the characteristics of online retailing are also integrated into other types of retailing. Third parties can also provide consumers with specific tools to compare products in other dimensions beyond price. There has been tremendous growth in different smartphone apps that provide information about ethical considerations and environmental impacts. Digitalization implies that information regarding various aspects of the exchange becomes available and can increase transparency in the flow of goods (Egels-Zandén and Hansson, 2015).

\section{Proliferation of transactions}

Digitalized transactions occur in various spheres of retailing both online and in fixed-store settings. Digitalization has, for example, enabled ordering processes to be fully conducted online (i.e., ecommerce) as a replacement for or complement to ordering by mail or phone or even to making the purchase in a fixed store. To an increasing extent, ordering by digital devices has become integrated with fixed-store processes, such as through click-and-collect (Herhausen et al., 2015). Furthermore, in stores, digitalization has provided consumers with new tools for navigating, such as by finding their way in stores through shopping lists ordered according to the aisles in the particular store provided by retailers or third parties and shareable between users (Voropanova, 2015). There has also been increased use of digital technologies that enable the replacement of cash payments with digital payments. In addition to various online transactions and credit and debit card payments in stores, there has been a proliferation of tools for mobile payments (Taylor, 2016). There are also various methods for generating digital receipts, even for fixed-store transactions. Retailers have provided handheld devices for extended self-service in stores, and there are efforts to enable usage of the smartphone as a scanner when conducting transactions in the physical store.

\section{New forms of distribution}

The digitalization of distribution has meant dramatic shifts in particular lines of business, such as music. Here, it involves a transformation of physical products into digital products, such as the transformation of vinyl records to $\mathrm{CDs}$, then to $\mathrm{mp} 3 \mathrm{~s}$, and then to streaming; thus, retailing now frequently includes more businesses that were originally conceived of as services. In addition to products that today are offered in fully digitalized form, there are other products that contain digital aspects. With labels such as EAN codes, QR codes, etc., it might be argued that almost all products contain a digital dimension in one way or another. This characteristic is also related to the distribution of products, where the digital and physical aspects of distribution are combined. In their review of the transport effects of e-commerce, Rotem-Mindali and Weltevreden (2013) find that mobility implications in terms of personal and freight transport differ depending on how broadly e-shopping is defined in the different studies (information search, transaction, delivery). Thus, in addition to being a question of definition, e-shopping should not be considered as necessarily involving a certain set of activities but rather commonly involving a combination of online and offline activities. In addition to 
traditional in-store purchase or home delivery, new forms of distribution for groceries using online ordering have emerged in recent years, such as click-and-collect and so-called 'click-and-drive' (Colla and Lapoule, 2012), where goods are picked up at a collection point. With mobile digital devices, new solutions for delivery services are emerging that also involve consumers in new forms of value cocreation (Bahn et al., 2015).

\section{Element II: Digitalization of actors}

Digitalization of actors consists of an increased intermixing of human and digital technologies on both the retailer and consumer sides. There is also an increased blurring of boundaries between retailers and consumers and new types of intermediaries, changing roles, and increased importance of different actors.

\section{Intermixing of humans and digital technologies}

New technologies enable new forms of agency in the context of retailing (see, e.g., Hagberg and Kjellberg, 2010; Cochoy et al., 2016). Agency cannot solely be attributed to the individual human customer but a network that involves humans and different objects and devices (e.g., shopping carts, computer stations, smart phones) that act collectively. Although this phenomenon is not new (which analysis of self-service reveals; see, e.g., Kjellberg and Helgesson, 2007; Cochoy, 2010), the contemporary proliferation of various types of devices in relation to shopping and consumption makes consideration of this quality even more important. As Belk (2014: 1107) argues, the digital world 'potentially changes the nature of humans, non-human things and the relations between them'. He means that the 'mediated technological portion of our self (e.g., as mediated by our wristwatch, smart phone, eyeglasses or digital appointment calendar) is becoming increasingly invisible and taken as a "natural" part of self' (p. 1110) and that consideration should be given to "the full entanglement of humans and things' (p. 1113). Thus, the notion of the 'consumer' entity should be reconsidered because the 'human body and digital information need to be thought of in conjunction with one another' (Boothroyd, 2009: 334 in Crewe, 2013: 774).

In addition to new forms of connection between humans and digital technologies, there are also examples of a changed notion of the individual. Cluley and Brown (2015) use Deleuze's (1992) concept of 'dividuals' and argue that information technologies lead not to the individualization of consumers but instead to a 'dividualisation'. People are considered 'not as individuals with emotions, attitudes, behaviours, but as data that can be divided and reassembled through analysis' (Cluley and Brown, 2015: 117). This reconceptualization leads to the application of devices that use these data traces to create 'new combinations of people, data and things' (Cluley and Brown, 2015: 117), which subsequently attach 'persons to the newly qualified sets of preferences and actions that are distributed in this hybrid space' (Cluley and Brown, 2015: 117).

\section{Blurring of boundaries}

The entanglement of humans and things not only changes the existing actors and their positioning (i.e., consumers on one side, retailers on the other) but also blurs boundaries between retailing and consumption, which is akin to discussions about the entanglement of production and consumption (e.g., Beer and Burrows, 2010; Ritzer and Jurgenson, 2010; Hartmann, 2016). Although it can be argued that the market economy has always been characterized by prosumption (Ritzer and Jurgenson, 2010), digitalization entails important transformations in the various ways in which production and consumption interrelate. In particular, digitalization provides new opportunities to connect businesses, employees and consumers and enables a blurring of their boundaries (cf. Ritzer and Jurgenson, 2010), which leads to difficulty in separating different actors' roles. In retailing, there are many examples of activities performed by the consumer that were previously, or in other settings, performed by the retailer and vice versa. In various forms of retailing, different actors (retailer personnel, customers, partners) can be involved to different extents, and customers can be co-producers and co-creators (Sorescu et al., 2011).

In addition, there has been a growing trend among firms to involve consumers in various aspects of the creation of value, a phenomenon called 'cocreation' (e.g., Prahalad and Ramaswamy, 2004; Zwick 
et al., 2008), 'coproduction' (e.g., Vargo and Lusch, 2004; Arvidsson, 2008), 'prosumption' (e.g., Toffler, 1980; Arvidsson and Colleoni, 2012; Collins, 2010; Cova and Cova, 2012), or 'working consumers' (Cova and Dalli, 2009; Dujarier, 2014; Cochoy, 2015). Although this phenomenon is not entirely new, it has been further strengthened by digitalization, which enables new ways to include the consumer in the value-creation process. For example, it enables consumers to handle more activities through, for example, self-service, collaborative co-production, 'organizational work' (Dujarier, 2014; Demirkan and Spohrer, 2014), and social commerce (Williams, 2014). Further, digitalization is an important aspect of different marketing approaches and forms of consumer competences, such as databases that enable relationship-marketing approaches, technologies that facilitate experiential approaches, and Internet usage that enables collaborative approaches (Cova and Cova, 2012).

\section{New actors, roles and relationships}

Digitalization also involves changes of intermediaries, i.e., they disappear or become new types of intermediaries (e.g., Bakos, 2001). Early predictions about the Internet indicated that it would involve a 'disintermediation' (e.g., Alba et al., 1997), i.e., the retailer would be replaced with direct contact between the manufacturer and the consumer. Although one might find examples of disintermediation in certain industries (see, e.g., Doherty and Ellis-Chadwick, 2010), a much more important effect is the development of new actors as well as the transformation of existing intermediaries' roles, such as providing other types of services and having a more digitalized market presence.

Digitalization has also changed the roles and relationships - and power relationships, in particularamong actors. Consumer roles, such as participation, voicing, sourcing (Schulten and Schaefer, 2015), and co-production have changed as a result of digitalization (Lehdonvirta, 2012). It has been argued that the proliferation of digital technologies, the Internet, and social media are related to growing consumer power (Labrecque et al., 2013). Doherty and Ellis-Chadwick (2010) claim that with digitalization, there is a change of power in favour of consumers due to 'decreasing information asymmetries', increased transparency, and increased possibilities that consumers might group together. The authors argue that while innovation and ideas connected to the Internet were previously primarily led by the supply side, now 'it will be the consumer, from the demand-side, who will be empowered to direct the way in which the revolution unfolds' (2010: 957). The use of digital technologies may also affect retailer-consumer relationships and how they are understood (Keeling et al., 2013), as well as relationships between retailer employees and managers (Pantano and Migliarese, 2014).

\section{Element III: Digitalization of settings}

The digitalization of the retail setting takes place through a change of retailing's traditional settings, i.e., the fixed store and the consumers' homes. In addition, the digitalization of settings also involves the emergence of new forms of settings, particularly those settings related to the proliferation of mobile devices in everyday life. Taken together, these developments lead to an increased intermixing of digital technologies, both in terms of time and place.

\section{Changes of traditional settings: The home and fixed stores}

One of the first aspects of retailing's digitalization was the proliferation of online stores, which was enabled by the increased use of PCs in consumers' homes. In recent years, the number of digital technologies used at home has increased dramatically, such as various innovations in television technology and mobile devices, including smartphones and tablets. These different devices have increased communicative capabilities and have been extended to different products and capabilities (Atzori et al., 2010). Thus, digitalization changes the use of digital technologies in everyday life and, in some cases, has a direct impact on retailing, e.g., home automation and the ability of things in the home, such as refrigerators, to 'talk' to a grocery retailer or to populate the consumer's shopping list.

As previously noted, digitalization is not restricted to online stores, and a number of digital technologies are becoming or will become part of shopping in fixed stores, e.g., digital signage, RFID, or digital kiosks (e.g., Shankar et al., 2011). Thus, as previously explained, there is an on-going digitalization of retailing's setting that is occurring through changes to the exchange and the actors, 
which takes place, to a great extent, in fixed stores. Digitalization will also change retail settings (Pantano and Viassone, 2015) and affect the level of customer satisfaction (Poncin and Mimoun, 2014). Initially, the emergence of the Internet was primarily considered in terms of posing a threat to brick-and-mortar stores, as it was believed that ordering online would considerably impact and possibly replace such conventional stores (Doherty and Ellis-Chadwick, 2010). However, there are numerous examples that reveal the contrary; the Internet is used as a tool to strengthen the physical store (Poncin and Mimoun, 2014; Stein and Ramaseshan, 2016; Pantano, 2016).

\section{New settings}

In addition to the changes to the home and the fixed store (i.e., the traditional settings for retailing), there are also examples of how digitalization can lead to new settings for retailing. There are currently two main forms of development of new settings enabled by digitalization. First, the proliferation of mobile devices makes retailing possible at more settings, e.g., at the bus or tram when commuting. These spaces become places in which searching for information, ordering, making payments, etc., can take place, activities that were previously more restricted to the fixed-store setting or to the home in front of a computer screen. As Lockhorn (2010) observes, '... as technologies like digital signage, mobile, and touch- and gesture-based interfaces bring new experiences to life, e-commerce has grown up. It's more than electronic commerce; it's everywhere commerce'. Second, the emergence of multior omni-channel retailing has brought a number of new retail locations in addition to the fixed store or home delivery, such as secure lockers, collection points, pick-up stations, and delivery points (see, e.g., Cullinane, 2009). Whereas so-called 'click-and-collect' implies a transformation of the existing retail settings (the fixed stores), the emergence of new points for collecting goods, such as click-anddrive (Colla and Lapoule, 2012), is an example of new, emerging retail settings. Other examples of changes in settings include new places, such as train stations, where goods can be ordered through devices for delivery at another time and place.

\section{Intermixing of settings}

These developments, the digitalization of traditional retail settings and the proliferation of new settings for retailing, have led to an increased intermixing and merging of the digital and physical in various settings. Licoppe (2013) describes how location-based mobile apps are examples of a "'merging" of the physical and the digital' (p. 24) that 'involves particular forms of spatial reflexivity' (p. 24). The Internet has led to a proliferation of new types of places for shopping and consumption online as well as to 'digital virtual places' that enable 'digital virtual consumption' (Denegri-Knott and Molesworth, 2010a: 58), such as online auctions and game worlds, spaces that combine both material and imaginary elements.

As Crewe indicates in her analysis of fashion and digital technologies, 'Certainly the bipolar narratives that dominated early e-commerce literature (physical versus virtual, clicks versus bricks, material versus immaterial) seem singularly unhelpful in understanding the complex spatialities and temporalities at work' (Crewe, 2013: 776). She argues that digital and physical spaces are interwoven and intertwined and thus, '... practices, processes, and products cannot be isolated from one another whether online or offline; printed and digitally mediated formats are co-connected, relational, and reveal mutual influence' (Crewe, 2013: 776).

\section{Element IV: Digitalization of offerings}

The distinction between products and services was problematized long ago (e.g., Levitt, 1981; Vargo and Lusch, 2004; Araujo and Spring, 2006), and digitalization further contributes to the blurring of these boundaries. Retailers typically offer what are traditionally considered both products and services, and the term 'offering' includes both to allow for this blurring. Digitalization contributes to changing offerings by including the digitalization of products themselves, i.e., the integration of digital technologies in what is offered. Digitalization also contributes to possible extensions to and the changing nature of the offerings as well as to how these offerings are priced and paid for.

\section{Changes of products and services}


As argued above, many products traditionally sold by retailers have been digitalized to a great extent, such as music, and this development is likely to continue to expand: '[M]any of the products and devices that we think of as stand-alone will achieve new functionality and utility by being connected to a network' (Masten and Plowman, 2010: 76). By integrating more and more digital features, products are transformed in many ways. However, although many products have become digitalized, material aspects remain. As Magaudda (2011) shows, even with regard to highly digitalized products such as music, digitalization does not lead to less materiality in consumers' practices; on the contrary, materiality remains an important part of these practices, as embodied in equipment such as mobile devices, earphones, etc., which are part of the picture whether the music comes from $\mathrm{mp} 3$ files or streaming services.

As with actors, increased hybridity applies to the notion of offerings, including material and virtual aspects. Denegri-Knott and Molesworth (2010a, 2010b) explain that their notion of 'digital virtual consumption' does not imply a Cartesian division of mind and body. Their example of eBay highlights that 'the material is always present in the form of computers, screens, cabling, keyboards and the embodied presence of the individual user... the material and the virtual are ever present; goods eventually arrive to the door' (Denegri-Knott and Molesworth, 2010a: 74). Simultaneously, with the use of digital signage, products might be explored in both analogue and digital ways.

\section{Extensions of offerings}

Digitalization also contributes to a possible extension of offerings. Amit and Zott (2001) describe complementarities as one source of value creation for e-businesses. These complementarities consist of possible bundling by extending the range of products and services offered and the opportunity to combine these 'on-line' and 'off-line'. The combination of brick-and-mortar and online stores has also provided new opportunities for increased profitability in assortment allocation, such as by providing different selections in different channels (see, e.g., Bhatnagar and Syam, 2014). Many retailers today offer different selections on their websites and fixed stores to provide a long-tail range of offerings online (Anderson, 2006) and a narrower range in the fixed store based on the most popular items that are typically kept in stock. With digital technologies, increased opportunities exist to extend the offerings during a fixed store visit with new forms of services enabled by these technologies (Saarijärvi et al., 2014; Renko and Druzijanic, 2014).

\section{New forms of pricing}

An increased blurring of product and service as part of the offering also creates challenges in pricing, e.g., whether the price should be based on a single unit, a subscription, etc. (Grewal et al., 2010). Prices and pricing are parts of the offering that may change considerably with digitalization. Digitalization creates a number of opportunities, such as customized promotions or dynamic pricing (see, e.g., Grewal et al., 2011), that may be used for online as well as in-store sales. Digitalization also enables individual communication of offerings and promotions, e.g., through the Internet, consumers' digital devices, or digital devices placed in stores, such as digital kiosks (e.g., Grewal et al., 2011). With digital tools, there is also a multiplicity in forms of price representation (see, e.g., Hagberg and Kjellberg, 2015), thus enabling new ways of displaying prices and the use of pricing techniques that are enabled by the same technologies.

\section{Conclusions and implications}

This paper has outlined the more all-encompassing transformations of digitalization of retailing by discussing how it influences four elements of the retailer-consumer interface. On the basis of the previous literature, it has analysed a) how exchanges are transformed through changes in communication, transactions and distribution; b) how actors are transformed through the intermixing of humans and digital technologies, the increased blurring of boundaries, and new actors, roles and relationships; c) how settings are transformed to include traditional and new settings as well as their intermixing; and d) how offerings are transformed through changes of products and services, extensions of offerings and new forms of pricing. As shown above, the transformation of retailing due to digitalization is extensive along the retailer-consumer interface and is likely to have significant implications for research and practice. Thus, the framework contributes to moving the retailing 
literature beyond discussions of digitalization as e-commerce and studies of specific, narrow aspects of digitalization. Drawing on this analysis, it is possible to discuss the theoretical and practical implications.

\section{Research implications}

Three main implications for research can be identified. First, the extensive changes of retailing due to digitalization require a combination of detailed analyses of how specific elements are transformed and how changes in these elements are part of a larger transformation. As suggested by our framework, there are mutual relationships between different elements of digitalization, which require sensitivity to their interdependence and development over time. Second, as suggested by our analysis, there is an emerging hybridity that also needs to be considered in research on the digitalization of retailing. We agree with Denegri-Knott and Molesworth's (2012:6) argument that there are 'conceptual pitfalls of reproducing a duality between what is physical or material consumption and what is digital virtual' and that these pitfalls should be avoided in defining digitalization in retail, i.e., dualistic separations between online/offline, digital/analogue, and material/virtual should be resisted in favour of more hybrid notions that combine and integrate these aspects in various ways. Third and finally, our framework provides a compromise between definitions of digitalization in retailing that are either too rigid or too loose. Too rigid definitions risk becoming obsolete over time, and too loose definitions risk becoming unusable because they provide no guidance at all. While scholars often call for proper and solid definitions that can be used over time and shared by everyone (Peterson and Balasubramanian, 2002), our analysis indicates that such a definition of digitalization in retailing is problematic, given its far-reaching and on-going transformation. Starting from a broad definition of digitalization as the integration of digital technologies in retailing, we have moved into a more specified framework of the digitalization of retailing in the retailer-consumer interface. Thus, we think that further explorations of the digitalization of retailing can fruitfully employ the suggested framework as a heuristic tool for further analysis.

\section{Practical implications}

The practical implications of the exploratory framework that can be identified are its ability to contribute to the analysis of its individual elements and the fact that it provides a holistic framework of analysis as well as guidance for the prospective and retrospective analysis of businesses and their development. For each of the elements included in the framework, examples are provided that can serve as guidance for present businesses to understand and manage changes due to digitalization. The framework may also work in a more holistic sense by providing managers in the retail industry with a way to understand and analyse how digitalization impacts their business at large. For example, managers can map their on-going activities using the framework to identify strengths and weaknesses in their current approaches to digitalization. Because they are constantly fed new information about digitalization, managers can also use our framework to categorize and make sense of this information to avoid becoming lost in the clutter of fads and fashions currently surrounding digitalization. Moreover, our framework can serve as a reminder for managers that digitalization is more than ecommerce and that the real business potential of digitalization lies in leveraging it to revitalize existing business models. Thus, the framework can be used to understand and make sense of businesses' development over time by framing and triggering analyses of such development both prospectively and retrospectively. For example, it can be used prospectively in the identification of future business opportunities or retrospectively as a framework for understanding how a business has developed in different areas due to digitalization.

\section{Limitations and future work}

This paper has outlined an overall framework for understanding how digitalization influences the retailer-consumer interface. Inevitably, this ambition restricts the possibility of providing an in-depth analysis of each of the four elements and the sub-categories of each element. Space limitations have also forced us to omit some of the practical examples that might have clarified certain arguments. Although there is a great need for research on specific, concrete and recent practical examples, there is also a danger in being too focused on contemporary practices that are quickly replaced. This difficulty 
has led us to emphasize the conceptual arguments rather than provide numerous practical illustrations. Finally, our intention has not been to provide a complete review of the existing literature but rather to provide an overall conceptual framework based on relevant research. There is, thus, a future need for more traditional studies regarding the digitalization of retailing as well as empirical tests of the claims put forth in this paper.

Additionally, while we have argued that the four elements included in our conceptual framework are mutually reinforcing, we have not explored the relationships between the different elements. Future studies should further explore the: i) actors-settings relationship (e.g., Denegri-Knott and Molesworth, 2013); ii) actors-exchanges relationship (e.g., Jung et al., 2014; Verhoef et al., 2015; Wang et al., 2015); iii) actors-offerings relationship (see Krafft et al., 2015); iv) settings-exchanges relationship (e.g., Cao and Li, 2015; Gazley et al., 2015); v) settings-offerings relationship (e.g., Grewal et al., 2011); and vi) exchanges-offerings relationship (e.g., Bhatnagar and Syam, 2014). Furthermore, future studies should explore the more complicated relations involving three or four of the elements, how changes in one element lead to potentially mutually reinforcing changes in the other elements, and how such changes evolve over time.

\section{Acknowledgements}

This research was supported by The Swedish Retail and Wholesale Council and The Swedish Research Council. Previous versions of the paper were presented at the Nordic Retail and Wholesale Conference in Stockholm in November 2014 and the EAERCD conference in Rennes in July 2015.

\section{References}

Alba, J., Lynch, J., Weitz, B., Janiszewski, C., Lutz, R., Sawyer, A. and Wood, S. (1997) "Interactive home shopping: consumer, retailer, and manufacturer incentives to participate in electronic marketplaces", Journal of Marketing, 61 (3), p38-53.

Amit, R. and Zott, C. (2001) "Value creation in e-business", Strategic Management Journal, 22 (6-7), p493-520.

Anderson, C. (2006) The Long Tail: How Endless Choice Is Creating Unlimited Demand, Random House Business Publishing House, London.

Araujo, L. and Spring, M. (2006) “Services, products, and the institutional structure of production”, Industrial Marketing Management, 35 (7), p797-805.

Arvidsson, A. (2008) “The ethical economy of customer coproduction”, Journal of Macromarketing, 28 (4), p326-338.

Arvidsson, A. and Colleoni, E. (2012) "Value in informational capitalism and on the internet", Information Society, 28 (3), p135-150.

Atzori, L., Iera, A., Morabito, G. (2010) “The internet of things: a survey”, Computer Networks, 54 (15), p27872805.

Bahn, K.D., Granzin, K.L., Tokman, M. (2015) "End-user contribution to logistics value co-creation: a series of exploratory studies”, Journal of Marketing Channels, 22 (1), p3-26.

Bakos, Y. (2001) "The emerging landscape for retail e-commerce”, Journal of Economic Perspectives, 15 (1), p69-80.

Beer, D. and Burrows, R. (2010) “Consumption, prosumption and participatory web cultures: an introduction", Journal of Consumer Culture, 10 (1), p3-12.

Belk, R. (2014) "Digital consumption and the extended self”, Journal of Marketing Management, 30 (11-12), p1101-1118.

Bhatnagar, A. and Syam, S.S. (2014) “Allocating a hybrid retailer's assortment across retail stores: bricks-andmortar vs online”, Journal of Business Research, 67 (6), p1293-1302.

Bodhani, A. (2012) "Shops offer the e-tail experience”, Engineering and Technology, 7 (5), p46-50. 
Boothroyd, D. (2009) "Touch, time and technics: Levinas and the ethics of haptic communications", Theory, Culture and Society, 26(2-3), p330-345.

Brynjolfsson, E., Hu, Y.J. and Rahman, M.S. (2013) "Competing in the age of omnichannel retailing”, MIT Sloan Management Review, 54 (4), p23-29.

Burt, S. and Sparks, L. (2003) "E-commerce and the retail process: a review", Journal of Retailing and Consumer Services, 10 (5), p275-286.

Cao, L. and Li, L. (2015) “The impact of cross-channel integration on retailers' sales growth", Journal of Retailing, 91 (2), p198-216.

Cluley, R. and Brown, S.D. (2015) "The dividualised consumer: sketching the new mask of the consumer", Journal of Marketing Management, 31 (1-2), p107-122.

Cochoy, F. (2010) "Reconnecting marketing to 'market-things': how grocery equipment drove modern consumption (progressive grocer, 1929-1959)", in Araujo, L, Finch, J. and Kjellberg, H. (Eds.), Reconnecting Marketing to Markets, Oxford University Press, Oxford, p29-49.

Cochoy, F. (2012) "The pencil, the trolley and the smartphone: understanding the future of self-service retailing through its sociotechnical history", in Hagberg, J., Holmberg, U., Sundström, M. and Walter, L. (Eds.), Nordic Retail Research: Emerging Diversity, BAS, Göteborg, p215-234.

Cochoy, F. (2015) "Consumers at work, or curiosity at play? Revisiting the prosumption/value cocreation debate with smartphones and two-dimensional bar codes", Marketing Theory, 15 (2), p133-153.

Cochoy, F., Trompette, P. and Araujo, L. (2016) "From market agencements to market agencing: an introduction", Consumption Markets \& Culture, 19(1), p3-16.

Coll, S. (2013) "Consumption as biopower: governing bodies with loyalty cards", Journal of Consumer Culture, $13(3), \mathrm{p} 201-220$.

Colla, E. and Lapoule, P. (2012) “E-commerce: exploring the critical success factors", International Journal of Retail \& Distribution Management, 40 (11), p842-864.

Collins, S. (2010) "Digital fair: prosumption and the fair use defence", Journal of Consumer Culture, 10 (1), p37-55.

Cova, B. and Cova, V. (2012) "On the road to prosumption: marketing discourse and the development of consumer competencies", Consumption Markets \& Culture, 15 (2), p149-168.

Cova, B. and Dalli, D. (2009) “Working consumers: the next step in marketing theory?", Marketing Theory, 9 (3), p315-339.

Crewe, L. (2013), "When virtual and material worlds collide: democratic fashion in the digital age", Environment and Planning A, 45 (4), p760-780.

Cullinane, S. (2009) "From bricks to clicks: the impact of online retailing on transport and the environment", Transport Reviews, 29 (6), p759-776.

Deleuze, G. (1992) "Postscript on the societies of control", October, 59 (Winter), p3-7.

Demirkan, H. and Spohrer, J. (2014) "Developing a framework to improve virtual shopping in digital malls with intelligent self-service systems", Journal of Retailing and Consumer Services, 21 (5), p860-868.

Denegri-Knott, J. and Molesworth, M. (2010a) “'Love it. buy it. sell it': consumer desire and the social drama of eBay”, Journal of Consumer Culture, 10 (1), p56-79.

Denegri-Knott, J. and Molesworth, M. (2010b) "Concepts and practices of digital virtual consumption”, Consumption Markets \& Culture, 13 (2), p109-132.

Denegri-Knott, J. and Molesworth, M. (2012) "Introduction to digital virtual consumption", in Molesworth, M. and Denegri-Knott, J. (Eds.), Digital Virtual Consumption, Routledge, New York, p1-8.

Denegri-Knott, J. and Molesworth, M. (2013) "Redistributed consumer desire in digital virtual worlds of consumption", Journal of Marketing Management, 29 (13-14), p1561-1579.

Dennis, C., Brakus, J. and Alamanos, E. (2013) “The wallpaper matters: digital signage as customer-experience provider at the Harrods (London, UK) department store", Journal of Marketing Management, 29 (3-4), p338-355. 
Doherty, N.F. and Ellis-Chadwick, F. (2010) "Internet retailing: the past, the present and the future", International Journal of Retail \& Distribution Management, 38 (11/12), p943-965.

Dujarier, M-A. (2014) “The three sociological types of consumer work”, Journal of Consumer Culture, published online before print April 8, 2014. doi:10.1177/1469540514528198.

Egels-Zanden, N. and Hansson, N. (2015) "Supply chain transparency as a consumer or corporate tool: supply chain transparency as a consumer or corporate tool", Journal of Consumer Policy, p1-19. doi:10.1007/s10603-015-9283-7.

Fors, A.C. (2010) "The beauty of the beast: the matter of meaning in digitalization", AI and Society, 25 (1), p2733.

Gazley, A., Hunt, A. and McLaren, L. (2015) “The effects of location-based-services on consumer purchase intention at point of purchase", European Journal of Marketing, 49 (9/10), p1686-1708.

Gloor, P. (2000) Making the E-Business Transformation, Springer, London.

Grewal, D., Ailawadi, K.L., Gauri, D., Hall, K., Kopalle, P. and Robertson, J.R. (2011) "Innovations in retail pricing and promotions", Journal of Retailing, 87 (Supplement 1), pS43-S52.

Grewal, D., Janakiraman, R., Kalyanam, K., Kannan, P.K., Ratchford, B., Song, R. and Tolerico, S. (2010) "Strategic online and offline retail pricing: a review and research agenda", Journal of Interactive Marketing, 24 (2), p138-154.

Grewal, D., Roggeveen, A. and Runyan, R.C. (2013) "Retailing in a connected world", Journal of Marketing Management, 29 (3-4), p263-270.

Hagberg, J. (2008) Flytande Identitet: NetOnNet och e-Handelns Aterkomst, Högskolan i Borås, Borås.

Hagberg, J. (2010) "Exchanging agencies: the case of NetOnNet”, in Araujo, L., Finch, J. and Kjellberg, H. (Eds.), Reconnecting Marketing to Markets, Oxford University Press, Oxford, p50-73.

Hagberg, J. and Kjellberg, H. (2010) "Who performs marketing? Dimensions of agential variation in market practice”, Industrial Marketing Management, 39 (6), p1028-1037.

Hagberg, J. and Kjellberg, H. (2015) "How much is it? Price representation practices in retail markets", Marketing Theory, 15 (2), p179-199.

Hartmann, B. J. (2016) "Peeking behind the mask of the prosumer: theorizing the organization of consumptive and productive practice moments", Marketing Theory, 16(1), p3-20.

Herhausen, D., Binder, J., Schögel, M., \& Herrmann, A. (2015) "Integrating bricks with clicks: retailer-level and channel-level outcomes of online-offline channel integration", Journal of Retailing, 91 (2), p309-325.

Hyunjoo, I. and Young, H. (2015) "Is this mobile coupon worth my private information?: Consumer evaluation of acquisition and transaction utility in a mobile coupon shopping context", Journal of Research in Interactive Marketing, 9 (2), p92-109.

Jung, K, Cho, Y.C., Lee, S. (2014) "Online shoppers' response to price comparison sites", Journal of Business Research, 67 (10), p2079-2087.

Keeling, K., Keeling, D. and McGoldrick, P. (2013) "Retail relationships in a digital age”, Journal of Business Research, 66 (7), p847-855.

Kim, H., Fiore, A.-M., Niehm, L.S. and Jeong, M. (2010) "Psychographic characteristics affecting behavioral intentions towards pop-up retail”, International Journal of Retail \& Distribution Management, 38 (2), p133-154.

Kjellberg, H. and Helgesson, C. (2007) "The mode of exchange and shaping of markets: distributor influence in the Swedish post-war food industry”, Industrial Marketing Management, 36 (7), p861-878.

Krafft, M., Goetz, O., Mantrala, M., Sotgiu, F. and Tillmanns, S. (2015) “The evolution of marketing channel research domains and methodologies: an integrative review and future directions", Journal of Retailing, 91 (4), p569-585.

Labrecque, L.I., vor dem Esche, J., Mathwick, C., Novak, T.P. and Hofacker, C.F. (2013) “Consumer power: evolution in the digital age", Journal of Interactive Marketing, 27 (4), p257-269.

Lehdonvirta, V. (2012) “A history of the digitalization of consumer culture”, in Molesworth, M. and Denegri Knott, J. (Eds.), Digital Virtual Consumption, Routledge, New York, p11-28. 
Levitt, T. (1981) “Marketing intangible products and product intangibles", Harvard Business Review, 59 (3), p94-103.

Licoppe, C. (2013) "Merging mobile communication studies and urban research: mobile locative media, 'onscreen encounters' and the reshaping of the interaction order in public places", Mobile Media \& Communication, 1 (1), p122-128.

Lockhorn, J. (2010) "Digitalization of retail" ClickZ, 4 May, available at: http://www.clickz.com/clickz/column/1711859/digitalization-retail.

Magaudda, P. (2011) "When materiality 'bites back': digital music consumption practices in the age of dematerialization", Journal of Consumer Culture, 11 (1), p15-36.

Masten, D.L. and Plowman, T.M.P. (2010) "Digital ethnography: the next wave in understanding the consumer experience", Design Management Journal, 14 (2), p75-81.

Moisander, J. and Eriksson, P. (2006) "Corporate narratives of information society: making up the mobile consumer subject”, Consumption Markets \& Culture, 9 (4), p257-275.

Osterwalder, A. and Pigneur, Y. (2002) “An e-business model ontology for modeling e-business", 15th Bled Electronic Commerce Conference, 17-19 June, Bled, Slovenia.

Pantano, E. and Migliarese, P. (2014) "Exploiting consumer-employee-retailer interactions in technologyenriched retail environments through a relational lens", Journal of Retailing and Consumer Services, 21 (6), p958-965.

Pantano, E. and Viassone, M. (2015) "Engaging consumers on new integrated multichannel retail settings: challenges for retailers", Journal of Retailing and Consumer Services, 25 (July), p106-114.

Pantano, E. (2016) "Engaging consumer through the storefront: evidences from integrating interactive technologies", Journal of Retailing and Consumer Services, 28 (January), p149-154.

Pauwels, K., Leeflang, P.S.H., Teerling, M.L. and Huizingh, K.R.E. (2011) "Does online information drive offline revenues?", Journal of Retailing, 87 (1), p1-17.

Peterson, R.A. and Balasubramanian, S. (2002) "Retailing in the 21st century: reflections and prologue to research", Journal of Retailing, 78 (1), p9-16.

Peterson, R.A., Balasubramanian, S. and Bronnenberg, B.J. (1997) "Exploring the implications of the internet for consumer marketing”, Journal of the Academy of Marketing Science, 25 (4), p329-346.

Piotrowicz, W. and Cuthbertson, R. (2014) "Introduction to the special issue information technology in retail: toward omnichannel retailing", International Journal of Electronic Commerce, 18 (4), p5-16.

Poncin, I. and Mimoun, M.S.B. (2014) "The impact of "e-atmospherics" on physical stores", Journal of Retailing and Consumer Services, 21 (5), p851-859.

Prahalad, C.K. and Ramaswamy, V. (2004) “Co-creation experiences: the next practice in value creation”, Journal of Interactive Marketing, 18 (3), p5-14.

Quelch, J.A. and Klein, L.R. (1996) “The internet and international marketing”, Sloan Management Review, 37 (3), p60-75.

Renko, S. and Druzijanic, M. (2014) "Perceived usefulness of innovative technology in retailing: Consumers' and retailers' point of view", Journal of Retailing and Consumer Services, 21 (5), p836-843.

Reynolds, J. (2002) "Charting the multi-channel future: retail choices and constraints", International Journal of Retail \& Distribution Management, 30 (11), p530-535.

Ritzer, G. (2001) Explorations in the Sociology of Consumption: Fast Food, Credit Cards and Casinos, Sage Publishing House, London.

Ritzer, G. and Jurgenson, N. (2010) "Production, consumption, prosumption: the nature of capitalism in the age of the digital "prosumer", Journal of Consumer Culture, 10 (1), p13-36.

Rotem-Mindali, O. and Weltevreden, J.W.J. (2013) "Transport effects of e-commerce: what can be learned after years of research?", Transportation, 40 (5), p867-885.

Saarijärvi, H. Mitronen, L. and Yrjölä, M. (2014) "From selling to supporting - leveraging mobile services in the context of food retailing", Journal of Retailing and Consumer Services, 21 (1), p26-36. 
Salkin, L.E. (1964) “Linear Programming for merchandising decisions", Journal of Retailing, 40 (4), p37-59.

Schoenbachler, D.D. and Gordon, G.L. (2002) "Multi-channel shopping: understanding what drives channel choice", Journal of Consumer Marketing, 19 (1), p42-53.

Schulten, M. B. and Schaefer, F. (2015) "Affective commitment and customer loyalty in crowdsourcing: antecedents, interdependencies, and practical implications", The International Review of Retail, Distribution and Consumer Research, 25 (5), p516-528.

Shankar, V. and Balasubramanian, S. (2009) "Mobile marketing: a synthesis and prognosis", Journal of Interactive Marketing, 23 (2), p118-129.

Shankar, V., Inman, J.J., Mantrala, M., Kelley, E. and Rizley, R. (2011) "Innovations in shopper marketing: current insights and future research issues", Journal of Retailing, 87 (Supplement 1), p29-42.

Shankar, V., Venkatesh, A., Hofacker, C. and Naik, P. (2010) "Mobile marketing in the retailing environment: current insights and future research avenues", Journal of Interactive Marketing, 24 (2), p111-120.

Sorescu, A., Frambach, R.T., Singh, J., Rangaswamy, A. and Bridges, C. (2011) "Innovations in retail business models", Journal of Retailing, 87 (Supplement 1), p3-16.

Stein, A. and Ramaseshan, B. (2016) "Towards the identification of customer experience touch point elements", Journal of Retailing and Consumer Services, 30 (May), p8-19.

Ström, R., Vendel, M. and Bredican, J. (2014) "Mobile marketing: a literature review on its value for consumers and retailers", Journal of Retailing and Consumer Services, 21 (6), p1001-1012.

Taylor, E. (2016), "Mobile payment technologies in retail: a review of potential benefits and risks", International Journal of Retail \& Distribution Management, 44 (2), p159-177.

Toffler, A. (1980) The Third Wave, Collins, London.

Vargo, S.L. and Lusch, R.F. (2004) "Evolving to a new dominant logic for marketing", Journal of Marketing, 68 (1), p1-17.

Verhoef, P. C., Kannan, P. K. and Inman, J. J. (2015) "From multi-channel retailing to omni-channel retailing: introduction to the special issue on multi-channel retailing", Journal of Retailing, 91(2), p174-181.

Voropanova, E. (2015) "Conceptualizing smart shopping with a smartphone: implications of the use of mobile devices for shopping productivity and value", The International Review of Retail, Distribution and Consumer Research, 25 (5), p529-550.

Wang, R.J.H., Malthouse, E.C., and Krishnamurthi, L. (2015) "On the go: how mobile shopping affects customer purchase behavior", Journal of Retailing, 91 (2), p217-234.

Watson, B.C. (2011) "Barcode empires: politics, digital technology, and comparative retail firm strategies", Journal of Industry, Competition and Trade, 11 (3), p309-324.

Williams, D.E. (2014) "Integrating the conceptual domains of social commerce: a meta-theoretical perspective", The International Review of Retail, Distribution and Consumer Research, 24 (4), p361-410.

Wrigley, N. and Currah, A. (2006) "Globalizing retail and the 'new e-conomy': the organizational challenge of e-commerce for the retail TNCs", Geoforum, 37 (3), p340-351.

Yadav, M.S. and Pavlou, P.A. (2014) "Marketing in computer-mediated environments: research synthesis and new directions", Journal of Marketing, 78 (1), p20-40.

Zhou, W. and Duan, W. (2015) "An empirical study of how third-party websites influence the feedback mechanism between online word-of-mouth and retail sales", Decision Support Systems, 76 (14), p14-23.

Zwick, D., Bonsu, S.K. and Darmody, A. (2008) "Putting consumers to work: 'co-creation' and new marketing govern-mentality", Journal of Consumer Culture, 8 (2), p163-196.

${ }^{[1]}$ In this paper, the term digitalization refers broadly to the integration of digital technologies into retailing: 'Digitalization: Integration of digital technologies into everyday life by the digitization of everything that can be digitized' [Businessdictionary.com 2014-10-22]. For more details, see the section titled 'Digitalization and the retailer-consumer interface'. 
1

2

3

4

5

6

7

8

9

10

11

12

13

14

15

16

17

18

19

20

21

22

23

24

25

26

27

28

29

30

31

32

33

34

35

36

37

38

39

40

41

42

43

44

45

46

47

48

49

50

51

52

53

54

55

56

57

58

59

60

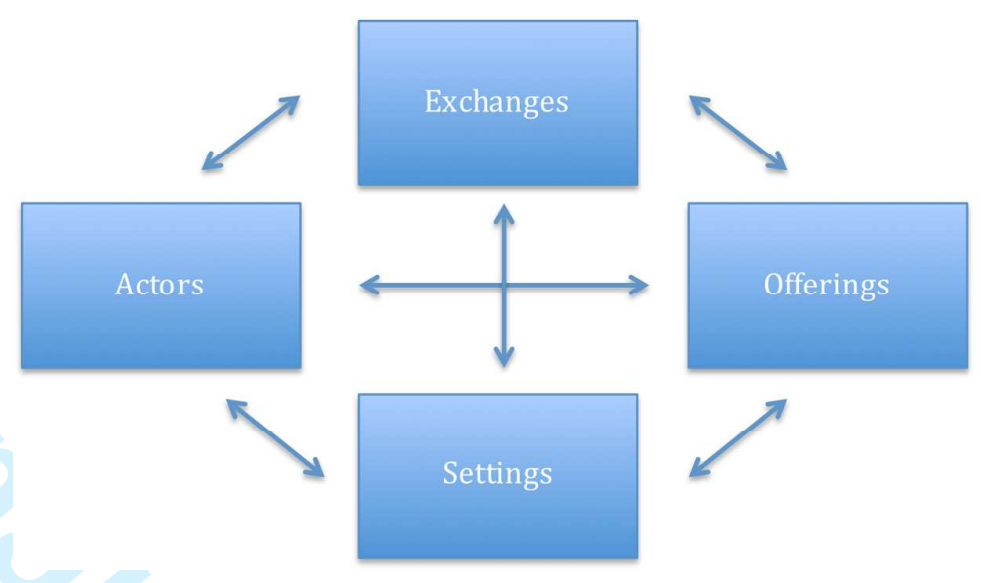

Figure 1 Conceptual framework 
Table 1 Summary of the literature employed

\begin{tabular}{|c|c|c|}
\hline Element & Transformation & Literature \\
\hline Exchanges & $\begin{array}{l}\text { - Changes of } \\
\text { communication } \\
\text { channels } \\
\text { - Proliferation of } \\
\text { transactions } \\
\text { - New forms of } \\
\text { distribution }\end{array}$ & $\begin{array}{l}\text { Bahn et al. (2015); Bhatnagar and Syam (2014); Brynjolfsson et al. } \\
\text { (2013); Cao and Li (2015); Coll (2013); Colla and Lapoule (2012); } \\
\text { Egels-Zandén and Hansson (2015); Gazley et al. (2015); Grewal et } \\
\text { al. (2013); Herhausen et al. (2015); Hyunjoo and Young (2015); Jung } \\
\text { et al. (2014); Pantano and Viassone, (2015); Peterson et al. (1997); } \\
\text { Piotrowicz and Cuthbertson (2014); Reynolds (2002); Rotem-Mindali } \\
\text { and Weltevreden (2013); Schoenbachler and Gordon (2002); Taylor } \\
\text { (2016); Verhoef et al. (2015); Voropanova (2015); Wang et al. } \\
\text { (2015); Yadav and Pavlou (2014); Zhou and Duan (2015). }\end{array}$ \\
\hline Actors & $\begin{array}{l}\text { - Intermixing of humans } \\
\text { and digital } \\
\text { technologies } \\
\text { - Blurring of boundaries } \\
\text { - New actors, roles and } \\
\text { relationships }\end{array}$ & $\begin{array}{l}\text { Alba et al. (1997); Arvidsson and Colleoni (2012); Arvidsson (2008); } \\
\text { Bakos (2001); Beer and Burrows (2010); Belk (2014); Boothroyd } \\
\text { (2009); Cluley and Brown (2015); Cochoy (2010); Cochoy (2015); } \\
\text { Cochoy et al. (2016); Collins 2010; Cova and Cova (2012); Cova and } \\
\text { Dalli (2009); Crewe (2013); Deleuze (1992); Demirkan and Spohrer } \\
\text { (2014); Denegri-Knott and Molesworth (2013); Doherty and Ellis- } \\
\text { Chadwick (2010); Dujarier (2014); Hagberg and Kjellberg (2010); } \\
\text { Hartmann (2016); Jung et al. (2014); Keeling et al. (2013); Kjellberg } \\
\text { and Helgesson (2007); Krafft et al. (2015); Labrecque et al. (2013); } \\
\text { Lehdonvirta (2012); Pantano and Migliarese (2014); Prahalad and } \\
\text { Ramaswamy (2004); Ritzer and Jurgenson (2010); Schulten and } \\
\text { Schaefer (2015); Sorescu et al. (2011); Toffler (1980); Vargo and } \\
\text { Lusch (2004); Verhoef et al. (2015); Wang et al. (2015); Williams } \\
\text { (2014); Zwick et al. (2008). }\end{array}$ \\
\hline Settings & $\begin{array}{l}\text { - Changes of traditional } \\
\text { settings } \\
\text { - New settings } \\
\text { - Intermixing of settings }\end{array}$ & $\begin{array}{l}\text { Atzori et al. (2010); Cao and Li (2015); Colla and Lapoule (2012); } \\
\text { Crewe (2013); Cullinane (2009); Denegri-Knott and Molesworth } \\
\text { (2010a); Denegri-Knott and Molesworth (2013); Doherty and Ellis- } \\
\text { Chadwick (2010); Gazley et al. (2015); Grewal et al. (2011); Licoppe } \\
\text { (2013); Lockhorn (2010); Pantano (2016); Pantano and Viassone } \\
\text { (2015); Poncin and Mimoun (2014); Shankar et al. (2011); Stein and } \\
\text { Ramaseshan (2016). }\end{array}$ \\
\hline Offerings & $\begin{array}{l}\text { - Changes of products } \\
\text { and services } \\
\text { - Extensions of offerings } \\
\text { - New forms of pricing }\end{array}$ & $\begin{array}{l}\text { Amit and Zott (2001); Anderson (2006); Araujo and Spring (2006); } \\
\text { Bhatnagar and Syam (2014); Denegri-Knott and Molesworth (2010a); } \\
\text { Denegri-Knott and Molesworth (2010b); Grewal et al. (2010); } \\
\text { Grewal et al. (2011); Hagberg and Kjellberg (2015); Krafft et al. } \\
\text { (2015); Levitt (1981); Magaudda (2011); Masten and Plowman } \\
\text { (2010); Renko and Druzijanic (2014); Saarijärvi et al. (2014); Vargo } \\
\text { and Lusch (2004). }\end{array}$ \\
\hline
\end{tabular}

